Tilmann Schlenther, Kai Martins-Turner, Joschka Felix Bischoff, Kai Nagel

\title{
Potential of Private Autonomous Vehicles for Parcel Delivery
}

Journal article | Accepted manuscript (Postprint)

This version is available at https://doi.org/10.14279/depositonce-10584

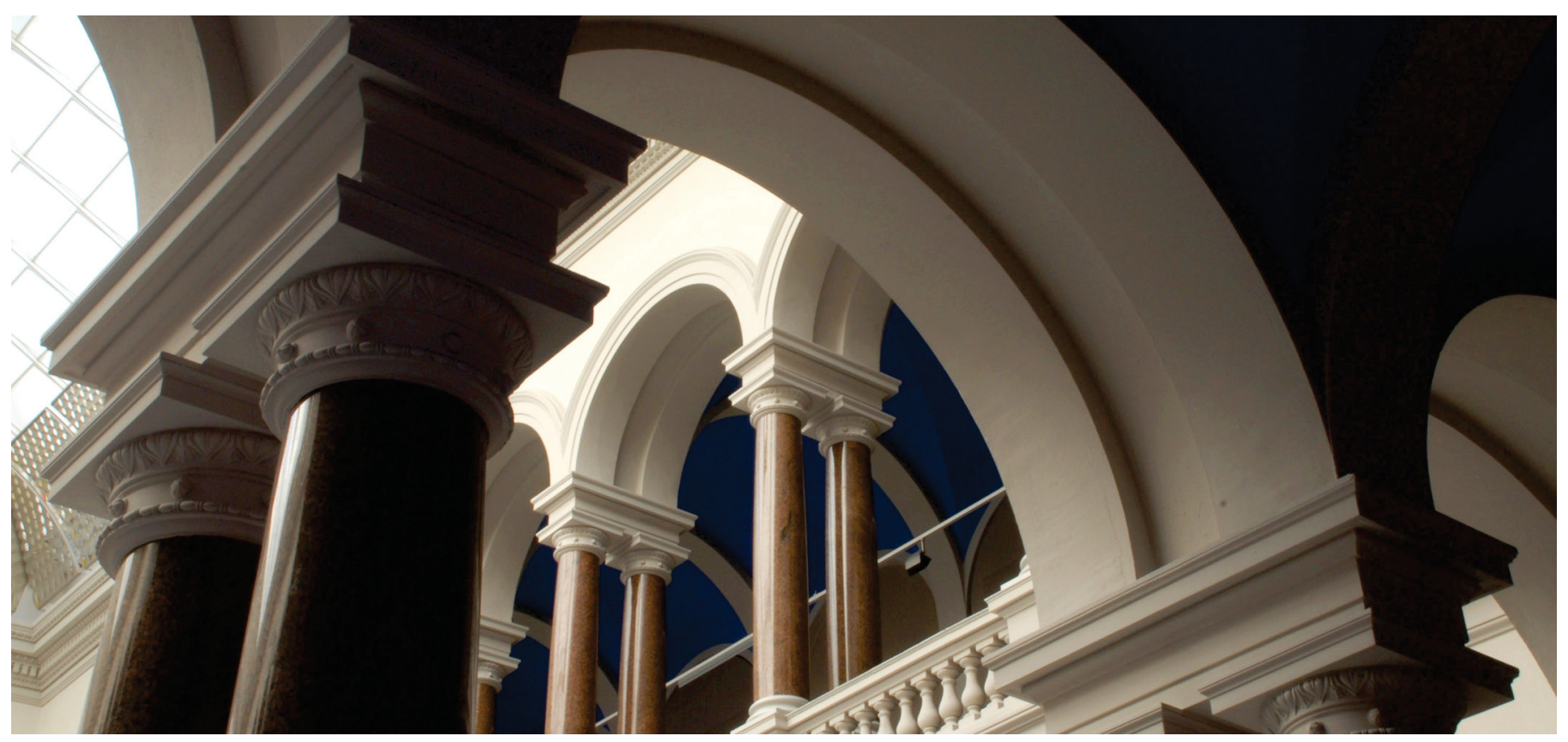

Schlenther, T., Martins-Turner, K., Bischoff, J. F., \& Nagel, K. (2020). Potential of Private Autonomous Vehicles for Parcel Delivery. Transportation Research Record: Journal of the Transportation Research Board. Copyright (C) National Academy of Sciences: Transportation Research Board 2020.

https://doi.org/10.1177/0361198120949878 


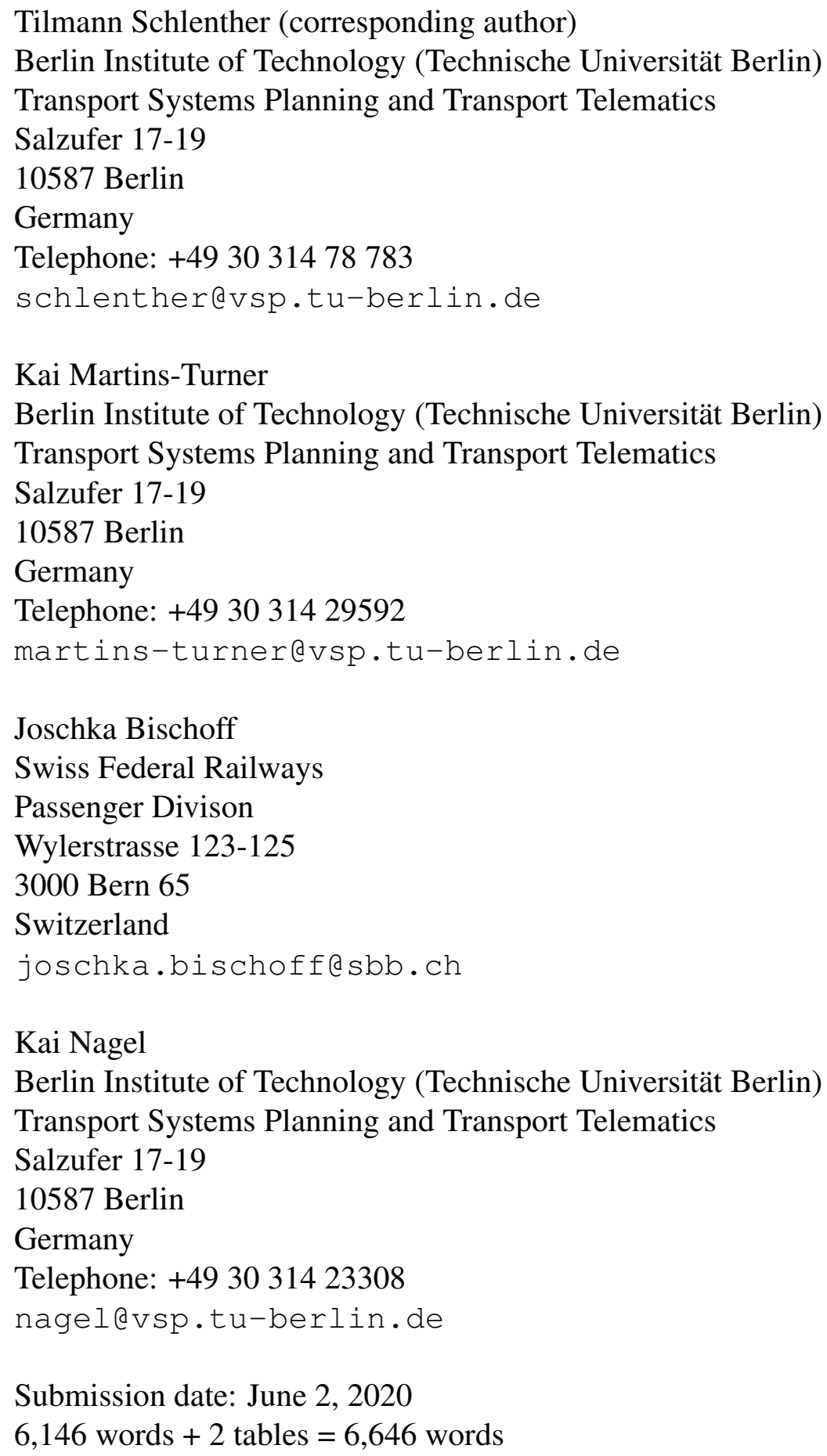




\begin{abstract}
Using the same vehicles for both passenger and freight transport, in order to increase vehicle occupancy and decrease their number, is an idea that drives transport planners and is also being addressed by manufacturers. This paper proposes a methodology to simulate the behavior of such vehicles within an urban traffic system and evaluate their performance. The aim is to investigate the impacts of resignation from fleet ownership by a transport service company operating on a city-wide scale. In the simulation, the service provider hires private autonomous cars for tour performance. Based on assumptions concerning the operation of such vehicles and transport service companies, the software MATSim is extended to model vehicle and operator behavior. The proposed framework is applied to a case study of a parcel delivery service in Berlin serving a synthetic parcel demand.

Results suggest that the vehicle miles traveled for freight purposes increase due to additional access and egress trips. Moreover, the number of vehicles en route is higher throughout the day. The lowering of driver costs can reduce the costs of the operator by approximately $74.5 \%$. If the service provider additionally considers the resignation from fleet ownership, it might lower the operation cost by another $10 \%$, not taking into account the costs of system transfer or risks like vehicle non-availability. From an economic perspective, the reduction of the overall number of vehicles in the system seems to be beneficial.

Keywords Freight, Autonomous Vehicles, Parcel Delivery, Fleet, Multi-Agent Transport Simulation
\end{abstract}




\section{INTRODUCTION}

Automation of driving is a widely discussed topic in both research and industry and is likely to have widespread impacts. Cars are expected to soon be used for more than just driving, allowing passengers to eat, sleep or work while traveling (I). Mobility services such as ride-hailing, centrally organized and demand-responsive, might become more important and restructure the urban transport market (2, 3, 4). In transportation planning, this is linked to the target of reducing the number of vehicles in the system. By sharing them between multiple people, the number of vehicles needed to satisfy the current private transport demand in Berlin could be reduced by a factor of up to 10 (5] 6). However, relatively high variable costs of shared autonomous vehicles, such as often-underestimated cleaning costs (I), might lead to a considerable share of vehicles remaining in private possession (7). Another way of reducing the urban fleet size is by utilizing a vehicle for more than just passenger purposes. While conventional cars spend most of the time parked at the curbside, autonomous vehicles (AVs) can serve other objectives while not in use by their owner.

In 2018, Toyota presented a new vehicle concept that was supposed to redefine not only the corporation's business strategy (by evolving from a manufacturer to a service provider) but the whole mobility market (8). Driven by the idea of using a vehicle for more than just one transport purpose, the interior was designed to be dynamic. This can be seen as one example of how a single vehicle can be used for both passenger and freight transport (9). Another approach to address diverse, dynamic requirements would be a modular setup of vehicles, allowing the rapid swap of passenger cabins for freight cabins. But why make the effort?

In freight traffic, automated driving has the advantage of potentially increasing the profit of transport service companies (TSC) by reducing driver wages (1] 10). For a TSC, outsourcing the fleet ownership might change the operational concept and has the potential to turn fixed costs into variable costs (11). In this paper, a simulation-based methodology is developed to estimate changes in tour planning as well as in operational cost structure by comparing the operation of a company-owned fleet with the hiring of AVs from other persons. In addition to the company perspective, the change in economic costs of the transport system's vehicle fleet is approximated. Will a TSC hire vehicles from a private persons? It could hire from another fleet operator instead. We do not investigate this question but want to take the hiring from private persons as the basic assumption as we want to investigate how to optimize usage of private vehicles.

As mentioned above, even with AVs and Mobility-as-a-Service companies on the market, private vehicle ownership will likely not totally disappear (6, 7). But by sharing their vehicle, owners can increase the system effectiveness and reduce vehicle kilometers traveled (12). With automation of the private vehicle sector, the number of vehicles needed decreases (5) 6). This effect is now supposed to get reinforced by deploying the same vehicles additionally for freight purposes. This is why this study concentrates on the use of private AVs instead of an On-DemandFleet.

Are time periods of idling private AVs large enough to perform freight tours? Does it make sense for a delivery service to resign from fleet ownership? How could an operation pattern of a vehicle look like when it serves multiple purposes? This study represents the development of a methodology to address these questions, by deploying a traffic simulation. It is applied to the use case of a parcel delivery in Berlin. To the knowledge of the authors, no similar simulation-based investigation has been conducted, yet. 


\section{METHODOLOGY}

The study relies on a simulation-based approach to evaluate the impacts of the change from the operation of a company-owned fleet to the borrowing of private automated vehicles. The framework used is MATSim (Multi-Agent Transport Simulation) (13) which is an open source software platform written in Java and is well-suited for dynamic transport systems (14). Its core functionality can be extended via multiple modules, of which the taxi module based on the dynamic vehicle routing problem (DVRP) and the freight module are of particular interest here.

\section{Transport Simulation Software}

In MATSim, every traveling person is modeled by an agent holding a set of plans, each of which can be seen as a draft of the agent's daily course. A plan consists of activities and legs in between them. In a mesoscopic mobility simulation that is based on a queue traffic flow model, the agents execute one of their plans. This plan is then assigned a score before plan adaption for a subset of agents takes place. By repeating this process for a predefined number of iterations, a stochastic user equilibrium can be approximated Nagel and Flötteröd (15).

In addition to this day-to-day-replanning, the DVRP module, on which the taxi module is based, allows modeling within-day-replanning where driver and vehicle behavior is spontaneous and might be unplannable. In contrast to the standard MATSim approach, different representations of agents and vehicles are required.(16, 17, 18) Using this approach, vehicles follow a schedule of tasks, which can be grouped in StayTasks (e.g. pickup, dropoff, waiting) and DriveTasks (empty or loaded) (16). In addition to the DVRP module, the taxi module allows modeling of the interaction between passenger and vehicle during pickup and dropoff. Schedules can be manipulated by the optimizer, which can be interpreted as the headquarters of a TSC. The optimizer is also responsible for mapping vehicles and requests (dispatch). In this study, passenger vehicles are considered to be privately owned. Consequently, these vehicles are dispatched only to their owner, and every request is served eventually (5).

The freight module in MATSim allows simulation of a TSC in the form of a carrier agent, for which the tour planning can be calculated by employing an interface to the JSprit open-source software for solving vehicle routing problems offline (19). Similar to a standard agent, the carrier has a set of plans that hold all tours calculated by Jsprit which are necessary to serve the delivery demand. Customer availability is modeled by a time window which the tour planning tries to account for. The fleet of the carrier agent can be specified by providing vehicle types and numbers but can also be set to 'infinite' for computation, in which case JSprit optimizes fleet size and composition given the vehicle routing problem (20). By employing the freight module, JSprit is provided with up-to-date travel times calculated in MATSim.

\section{Representation of Freight Tour Elements and Definition of a Tour}

Originally, the data model of a tour within the freight module does not correspond to the data model of a taxi's schedule. Thus, after computation, freight tour elements need to be converted into tasks that can be put into a taxi's schedule.

The taxi module provides different task types for empty and occupied trips. However, in order to be able to distinguish conventional taxis tasks from freight tasks, new task types were defined. In this work, a modular car setup is assumed which allows swapping the passenger cabin for a freight container within a reasonable amount of time. Therefore, vehicles arriving at the depot get retooled both before and after performing the tour. This can be interpreted as getting equipped 
with an already-loaded freight container before the tour start or with a passenger cabin after the tour, respectively. Retooling is assumed to last 15 minutes.

In contrast to the definition of a freight tour in the freight module, for the analysis and the dispatch in this work, the access and egress trips to and from the depot are considered to be part of the freight tour. Consequently, all tours are longer compared to when they are computed. However, the egress trip might be skipped if there is enough time to perform several tours in a row (see the following section for details).

\section{Operation Pattern of the Service Provider and the Vehicles}

For the operational pattern of the vehicle and the parcel service, the following assumptions are made:

1. Freight tours are calculated offline ("during the night"). This means JSprit is run before the traffic simulation and tours are converted into queues of taxi-compatible tasks. Online calculation of tours, i.e. building a tour by deploying JSprit whenever a vehicle gets available, can not be performed at a city-wide scale in a reasonable amount of time, at the moment. An online calculation of tours could have the benefit to adopt tour duration to the vehicle's availability time frame and the possibility of optimal assignment of delivery demand points. However, the authors are willing to address this challenge in future extensions to this study.

2. Tours can only be executed within a given global time window. This represents the working time window of the TSC headquarters and can possibly be configured to last the whole day.

3. Before requesting a freight tour for the first time in the day, vehicles first drop off their passengers.

4. Each vehicle holds information on time and location of the next planned usage by its owner. This information may be programmed in the morning by the owner via an app.

5. The process of parcel delivery is automated. For instance, the vehicle could place parcels into specially made delivery boxes which would be accessible at each house block. This has the advantage that customer availability is not essential for successful delivery by the AV. It is assumed that the duration of the dropoff process does not change with automation.

For the majority of parcels, the delivery locations are known a day in advance; therefore, tours can be planned offline. As a result, tours will not be interrupted; i.e. vehicles either serve their passenger (owner) or a parcel service, but not both at the same time. For instance, when a vehicle is on a delivery tour and the owner opens a request, the latter has to wait for the vehicle to finish the current tour.

Idle vehicles request tours of the parcel service, which is executing the dispatch according to individual optimization criteria. The service provider's headquarters is represented by the implementation of a FreightTourManager (manager). For this paper, the manager has central knowledge of all remaining tours at each depot, sorted by urgency which is operationalized by the end time of the last delivery's time window in a tour. The manager is assumed to be responsible for assuring 
that the return of the vehicle to it's owner is on time. While dispatching, the manager needs to respect this constraint as well as the global delivery time window.

After each passenger drop-off, a freight tour request is initiated. The manager has access to the information about the time and location of the owner's next anticipated use of the vehicle. In this paper, the following heuristic is used for vehicle to freight tour dispatch:

1. For each freight tour request, determine the spatially closest three depots to the vehicle's current location and sort them in ascending order.

2. Assess for each undispatched tour per depot whether the vehicle has enough time to perform it. If that is the case, assign the vehicle to the tour and stop the search.

To anticipate whether there is enough time left for the vehicle to perform the tour, both the access trip and the return trip from the last delivery of the tour to the depot are considered. In addition, a time buffer of five minutes is included in the calculation. If no fitting tour is found, the request is rejected. In a real world scenario, the TSC would consider neglecting the vehicle's freight tour request upfront in order to optimize operation costs. An example for a situation where neglect might be advantageous is when the total number of tours to execute is considerably lower than the demand level. Moreover, the number of requests might be dynamically anticipated. This kind of operational cost minimization is simplified in this work by setting a spatial and a time constraint on the access leg to the tour depot. At the time of request submission, the vehicle has to be within a euclidean distance of ten kilometers to the depot and be able to reach it within twenty minutes based on up-to-date travel times. The fact that only three depots are considered also limits access trips across the city. Otherwise, the request is rejected. Tours can be dispatched before the global delivery time window starts. If a vehicle arrives at the depot before the global delivery time window starts, it needs to wait until the retooling task begins.

If a fitting tour is found, the manager returns it to the scheduler, which is an extension by the taxi module to the optimizer in the DVRP module. The scheduler can manipulate the vehicle's schedule online, that means in real time. In the scheduler, the freight tour is inserted into the vehicle in its entirety and does not get re-routed. Thereafter, the vehicle performs the freight tour. At the time of return to the depot, but before the vehicle is retooled with the owner's passenger cabin, the manager investigates whether the same depot has another fitting tour available. This means that several freight tours can be performed consecutively without returning to the owner. If the depot does not have a fitting tour, the vehicle is retooled. Afterwards, it opens a new freight tour request for which the just-served depot is excluded. This operation patterns assures that the owner will always be provided with the same passenger cabin as they are used to driving. Figure 1 illustrates how a freight tour is built in to a vehicle's schedule when a request (represented by a green trapezoid) leads to a dispatch of a fitting tour (see blue arrows). Red arrows display what happens if no fitting tour can be provided.

This operation pattern assumes that the supply of vehicles is always large enough, i.e. all freight tours can be performed within the scope of one day. In the real world however, the number of available AVs might not be sufficient. In consequence, the TSC would raise the price it pays to the vehicle owners. This price dynamic is complex and can depend on many variables such as vehicle availability, workload (number of freight tours), day time, vehicle capacity and cost parameters, urgency of deliveries etc. Currently, the price dynamic can not be modeled in detail and the authors think that it should be subject to an own dedicated study. Furthermore, one aim 
of this study is to find out whether the time budgets of private vehicles are large enough to allow multi-purpose-operation in the first place. Therefore, it is assumed that the amount of available vehicles is always sufficient. In a capital city like Berlin, with around one million private cars at the moment, this assumption seems reasonable with respect to the vision of the automation in the private vehicle sector.

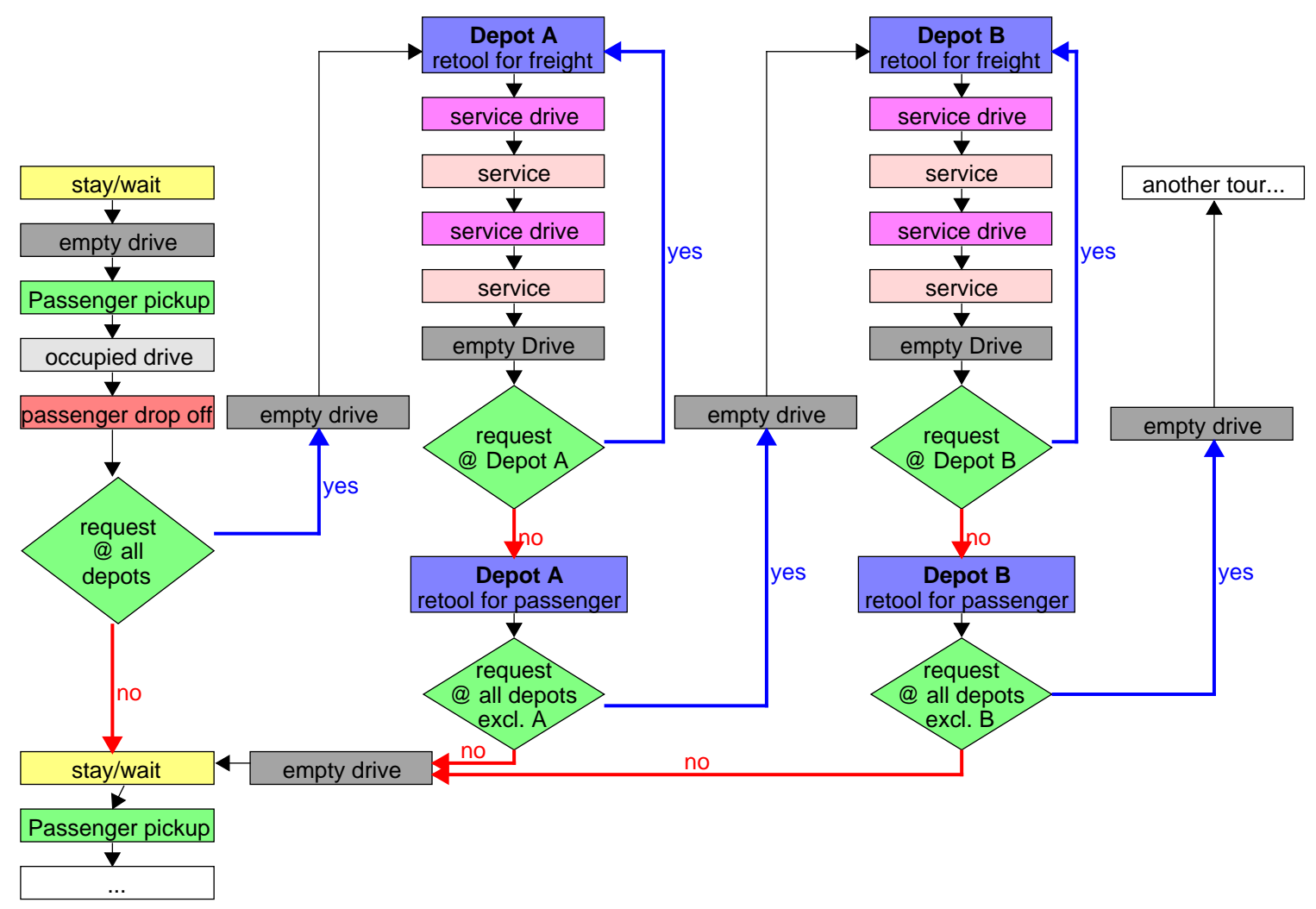

FIGURE 1 Logical scheme of the operation pattern of a vehicle

\section{SIMULATION SETUP}

The introduced framework for modeling on-demand fleet behavior of TSCs is applied to the MATSim Open-Berlin-Scenario (available under https://github.com/matsim-vsp/matsim-berlin) (21). A synthetic parcel demand based on census data is served by a single parcel delivery operator. The following section describes how the scenario is adopted and extended, as well as which assumptions are made.

\section{Depots}

In lieu of detailed data on the currently existing city-depots in Berlin of DHL Paket GmbH, the main parcel delivery operator, the following assumptions are made. Firstly, a data set of 200 post offices in Berlin belonging to several operators is obtained by querying OpenStreetMap (22) via Overpass Turbo API(23). This data set is then reduced to 23 offices of DHL Paket GmbH, one for each district in Berlin. Criteria for the selection of offices include a good connection to the major road system and preferably a high amount of space available, for example a backyard or a parking 
lot. corresponding depot and shaped by black borderlines.

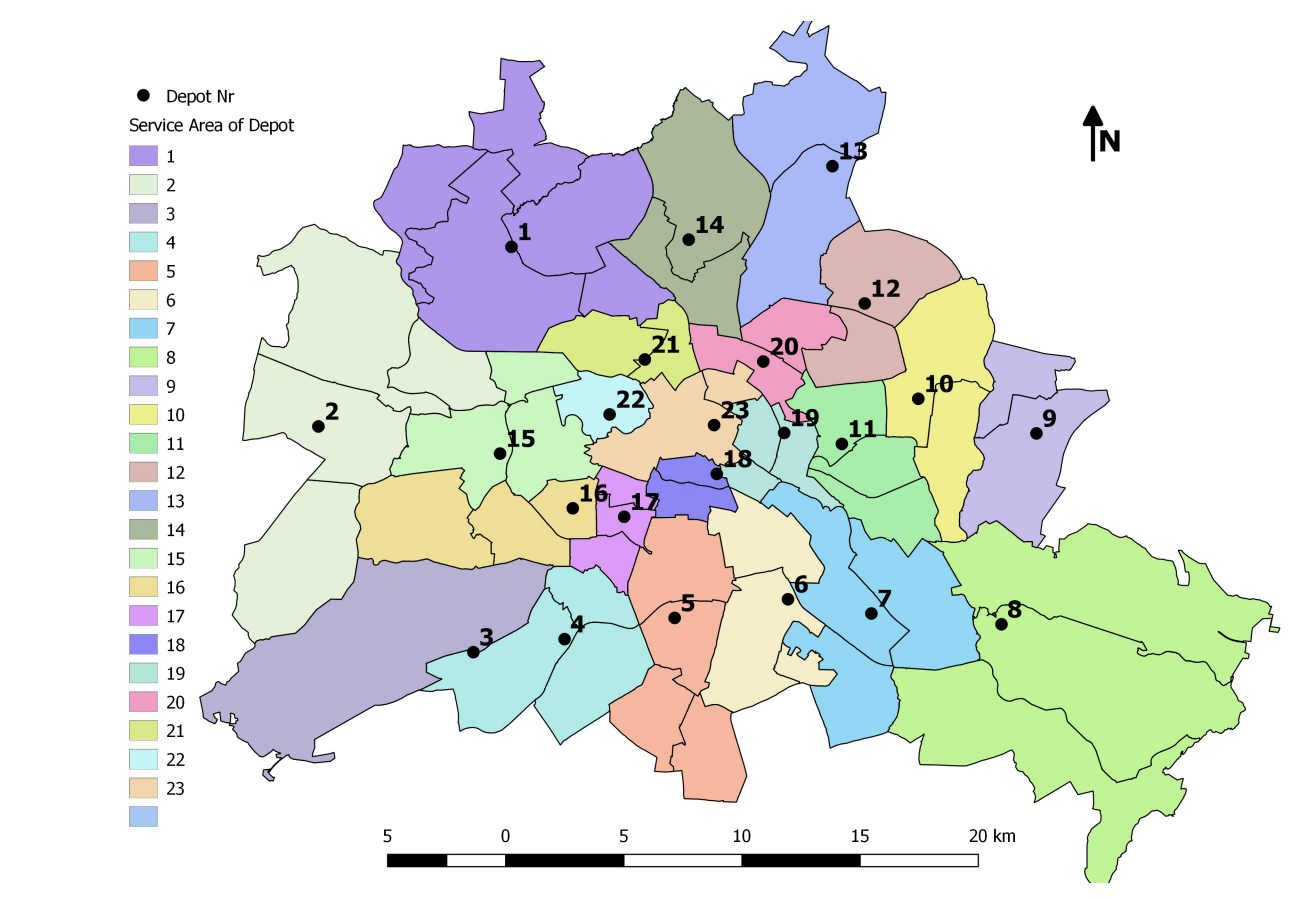

FIGURE 2 Location and service areas of depots, based on (24)

\section{Transport Network}

Since modeling a large fleet of dynamically routing vehicles is computationally expensive, the feature of NetworkChangeEvents is used (13, 20). This allows modeling only a subset of the demand while keeping realistic travel times, which are available as link attributes per time slice. As a consequence, congestion effects of modeled vehicles can not be examined in detail. are not defined on the level of the 23 districts of Berlin, but rather on the city's official 60 regional statistical zones (24). For each zone, a carrier agent is created, leading to tours which do not cross border lines (see black lines in figure 2). These types of service areas may not persist in the future of parcel delivery, but in the recent past, tour planning was based on restricted areas of sibility. Thus, this projection seems to be appropriate for this simulative approach.

Figure 2 shows the location of the depots as well as the service areas, colored by their

\section{Parcel Demand}

The demand of parcels is derived out of Thaller (25) and contains deliveries to both private persons and enterprises. Firstly, it is mapped to the scenario network and then deliveries are assigned to carriers. The resulting demand comprises 104,619 deliveries that cover 394,800 parcels, as a delivery has a capacity of between 1 and 12 parcels. The global delivery time window of the parcel delivery is set to start at 8 a.m. and terminates at 6 p.m. For roughly 85,800 of the deliveries, the customer availability time window lasts from 8 a.m. to 2 p.m., for approximately 12,500 of the deliveries is lasts from 8 a.m. to 10 a.m., and for the rest from 10 a.m. to 12 p.m. For each delivery

In order to reduce the computation time in tour planning, the service areas of the depots 
$s$ the duration $t_{s}$ in seconds is dependent on the capacity demand and computed by the following 2 equation:

$$
t_{s}=60+\text { capacityDemand } * 60 \text {. }
$$

\section{Vehicle Configuration}

As mentioned above, a modular car setup is assumed. In this work, two different vehicle types are considered which represent the current type vehicle types used for passenger transport and parcel delivery. For the both tour planning before the simulation and also the cost analysis as post process, cost parameters are used as shown in Table 1 . The calculation of cost parameters is based on Planco Consulting GmbH et al. (26). With this method, one half of the asset cost is deducted over time and the other half is deducted over mileage. For the 'car', the basis is a VW Golf 1.41 Trendline and the 'van' is based on a Mercedes CDI Sprinter. The overhead costs $O_{T S C}$ per vehicle and per day need to be borne entirely by the TSC independently on the operation pattern. They include all costs for fleet management. The difference between the private fixed cost parameter $\beta_{f i x_{P}}$ and the fixed cost parameter $\beta_{f i x_{T S C}}$, which is used for tour planning and operation cost analysis, lies in the tax rate of $19 \%$. The parcel capacity of delivery vans is derived from Zhang et al. (27) and cut in half for the car vehicle type. The time cost parameter $\beta_{\text {time }}$ only consists of driver costs. Thus it is set to zero for all AV simulations. These parameters represent input values for the tour planning with JSprit. Moreover, an infinite fleet size is defined for every carrier, leading to JSprit optimizing the number of tours and vehicles when performing all deliveries (19, 20), also shown in 2. The problem of sizing a shared vehicle fleet is also addressed by Vazifeh et al. (28) for passenger transport, given a point-to-point demand with set departure times. However, for this study it is assumed that private persons possess one autonomous vehicle each. The private fleet size consequently is set by the number of persons, as no sharing for the passenger transport sector is modeled. For the freight transport sector, the necessary fleet size is computed by the tour planning software JSprit. In addition to accounting for vehicle and demand availability time window constraints, this also accounts for a capacity constraint. The availability time window of vehicles is set according to the global delivery time window. Thus, JSprit calculates with a departure at 8 a.m.

TABLE 1 Vehicle Cost Parameters

\begin{tabular}{c|c|c|c|c|c|c} 
& $\begin{array}{c}\text { Private } \\
\text { Vehicle Type }\end{array}$ & $\begin{array}{c}\text { TSC } \\
\text { cixed }\end{array}$ & $\begin{array}{c}\text { Fixed } \\
\text { Overhead }\end{array}$ & $\begin{array}{c}\text { Time } \\
\text { Costs }\end{array}$ & $\begin{array}{c}\text { Distance } \\
\text { Costs }\end{array}$ & Capacity \\
& $\beta_{f i x_{P}}$ & $\beta_{f i x_{T S C}}$ & $\begin{array}{c}\text { Costs } \\
\text { OTSC }\end{array}$ & $\beta_{\text {time }}$ & $\beta_{\text {dist }}$ & cap \\
& {$[€ / \mathrm{d}]$} & {$[€ / \mathrm{d}]$} & {$[€ / \mathrm{d}]$} & {$[€ /$ veh-h] } & {$[€ / 100 \mathrm{~km}]$} & {$[$ parcels] } \\
\hline Van & 9.56 & 8.03 & 17.47 & 17.64 & 21.85 & 230 \\
Autonomous Van & 9.56 & 8.03 & 17.47 & 0 & 21.85 & 230 \\
Autonomous Car & 5.1 & 4.29 & 17.47 & 0 & 11.81 & 115
\end{tabular}

\section{Simulation Runs and Travel Demand}

To understand the possible impact of autonomous vehicles for parcel delivery, a comparison to the current situation is necessary. In the "Base Case", freight tours are performed by typical delivery vans that are owned and operated by the TSC. As the setup and cost structure of private 


\section{TABLE 2 Simulation Runs}

\begin{tabular}{c|c|c|c|c}
$\begin{array}{c}\text { Simulation } \\
\text { Run }\end{array}$ & $\begin{array}{c}\text { Tour } \\
\text { Count }\end{array}$ & Private Fleet & TSC Fleet & $\begin{array}{c}\text { Total } \\
\text { \#Vehicles }\end{array}$ \\
\hline Base Case & 1,814 & 14,000 Cars & 1,814 Vans & 15,814 \\
Hired Van & 1,818 & $\begin{array}{c}1,751 \text { autonomous Vans }+ \\
\text { 12,249 autonomous Cars }\end{array}$ & $\begin{array}{c}1,751 \text { autonomous } \\
\text { Vans }\end{array}$ \\
Hired Car & 3,478 & 14,000 autonomous Cars & 2,704 autonomous Cars & 14,000 \\
Own AV Car & 3,478 & 14,000 Cars & 3,478 autonomous Cars & 17,478
\end{tabular}

autonomous vehicles is still a subject of uncertainty, several policy cases are defined. In the policy case "Hired Van", the cost structure of delivery vehicles remains the same as the "Base Case", with the exception of driver costs ceasing to exist. That also means that the corresponding vehicle owners are assumed to pay van-like cost structures for their vehicles. However, for the cost analysis, every private vehicle owner that does not lend his or her vehicle is assumed to possess a typical car. In the policy case "Hired Car", parcel deliveries are performed by private autonomous cars. In order to be able to interpret the impacts of a TSC resigning from fleet ownership and properly distinguish from impacts coming from a different vehicle set up, another policy case "Own AV Car" is examined in which the company operates its own fleet of autonomous cars.

As the section Transport Network points out, only a portion of the private transport demand contained in the Open-Berlin-Scenario is simulated due to computation time minimization. The relevant fraction of the demand is represented by the owners offering their private $\mathrm{AV}$ for freight transport.

To determine the subset of agents, car users are filtered out of the one percent Open-BerlinScenario (21) in a first processing step. Their plans are fixed. As no reaction of the TSC to an insufficient number of available AVs is modeled, the number of car-users (and thus the number of $\mathrm{AVs}$ ) is determined in a trial-and-error process. Step by step, the number of agents is increased by 1,000 until all tours can be performed. As parcel capacity is at its minimum and the number of tours consequently at its maximum in the policy case "Hired Car", this simulation run determines the number of agents representing private AV owners, which results in the value of 14,000.

In order to make the agents use AVs instead of conventional cars, for simulations "Hired Van" and "Hired Car" every leg of mode car is converted to the AV mode except for legs whose departure and arrival links are equal. In the latter case, it is assumed that agents walk, in order to give their vehicle time to operate for freight purposes. Roughly $0.7 \%$ of the car users have at least one leg of that kind in their plan. Pickup and drop off durations are both set to 60 seconds. In addition to the passenger transport demand, parcel delivery is modeled. In the "Base Case" and in "Own AV Car", each freight tour is performed by a company-owned fleet and all private vehicle owners use conventional cars, resulting in 15,418 and 17,478 vehicles in the system, respectively (see tour count in table 2). In the runs "Hired Van" and "Hired Car", there is no company-owned fleet resulting in an overall amount of 14,000 vehicles in the system. In the column 'TSC Fleet' of table 2, the amount and type of vehicles are represented that do perform the freight tours in the end. As one can recognize, in the "Hired" cases one vehicle can perform several tours per day, leading to the number of vehicles being lower than the number of tours; especially when tours are shorter as a consequence of a lower capacity as in "Hired Car". 


\section{RESULTS}

The simulation setup is based on a fixed system state (see Transport Network section) but includes a high share of the original demand of car users that are all allowed to re-route at once. This means the change in travel distance and travel time of the private car owners can not be interpreted properly. Moreover, the plans of the private owners are not modified, thus their legs are considered to be stable throughout the simulations and are cut out of investigation in the following calculations. However, both the automation of vehicles and the change in the operation pattern of the TSC have an impact on the transport system's vehicle fleet composition and size. Thus, in order to get an idea of the impact on the transport system as a whole, the time-variation of vehicles en route and busy vehicles is investigated. In order to evaluate the different fleet operation pattern from the operator's view, tour distance and time are analyzed and operation costs estimated and compared to economic costs.

\section{Impacts on the Traffic System}

As mentioned above, the interpretation of impacts on the traffic system must be limited to the operational perspective on the vehicle fleet. However, the waiting time that owners experience as a consequence of freight tours taking longer than expected can be determined. In the "Hired Van" case, 54 owners have to wait with an average time of four minutes. In the "Hired Car" case, 57 out of the 2,704 vehicle owners experience a waiting time with an average value of approximately 17.5 minutes.

Figure 3 shows the time variation of percentage of vehicles en route and of busy vehicles. Busy means either serving a passenger including pickup and drop off or serving the TSC and not waiting on the curbside. As mentioned above, the overall fleet size varies between the simulation runs. One can see that when operating smaller vehicles, deliveries with customer availability starting from 10 a.m. lead to a second wave of vehicles en route (slight increase of green and red curve). The overall difference between the cases in the time-variation of vehicles en route is relatively small. Disregarding the sudden peak at 8 a.m., which is a modeling artifact resulting from all freight tours being started at the same time, the percentage of vehicles en route is higher throughout the day if the TSC does not use its own vehicles for both vehicle sizes respectively (red and blue line). Regarding the variation of busy vehicles on the right side of the figure, a smaller vehicle size seems to increase the maximum level. Hiring vehicles seems to broaden the top of the curve. That means the usage of vehicles is spread over time more evenly. This is a consequence of fewer tours starting at 8 a.m. if the TSC hires vehicles from private persons.

\section{Impacts on Tour Operation}

Resigning from fleet ownership has the consequence that vehicles have to perform access and egress trips to and from the depot. This is the major difference in the operation pattern. Figure 4 shows the composition of tour distance and tour duration over all simulations. Regarding the tour distance, the impact of the resignation from vehicle ownership is reflected by an increase of $53 \%$ of the driven kilometers when operating vans, or $61 \%$ when operating cars. Moreover, the reduction of vehicle capacity by half approximately doubles the number of tours and increases the tour distance by $50-60 \%$.

For all simulations, the time needed to perform the parcel drop-off is assumed to be constant. With the tour distance increasing, the amount of time spent driving also increases. Additionally, when hiring private autonomous vehicles, the TSC needs to retool the vehicles at the depot, 

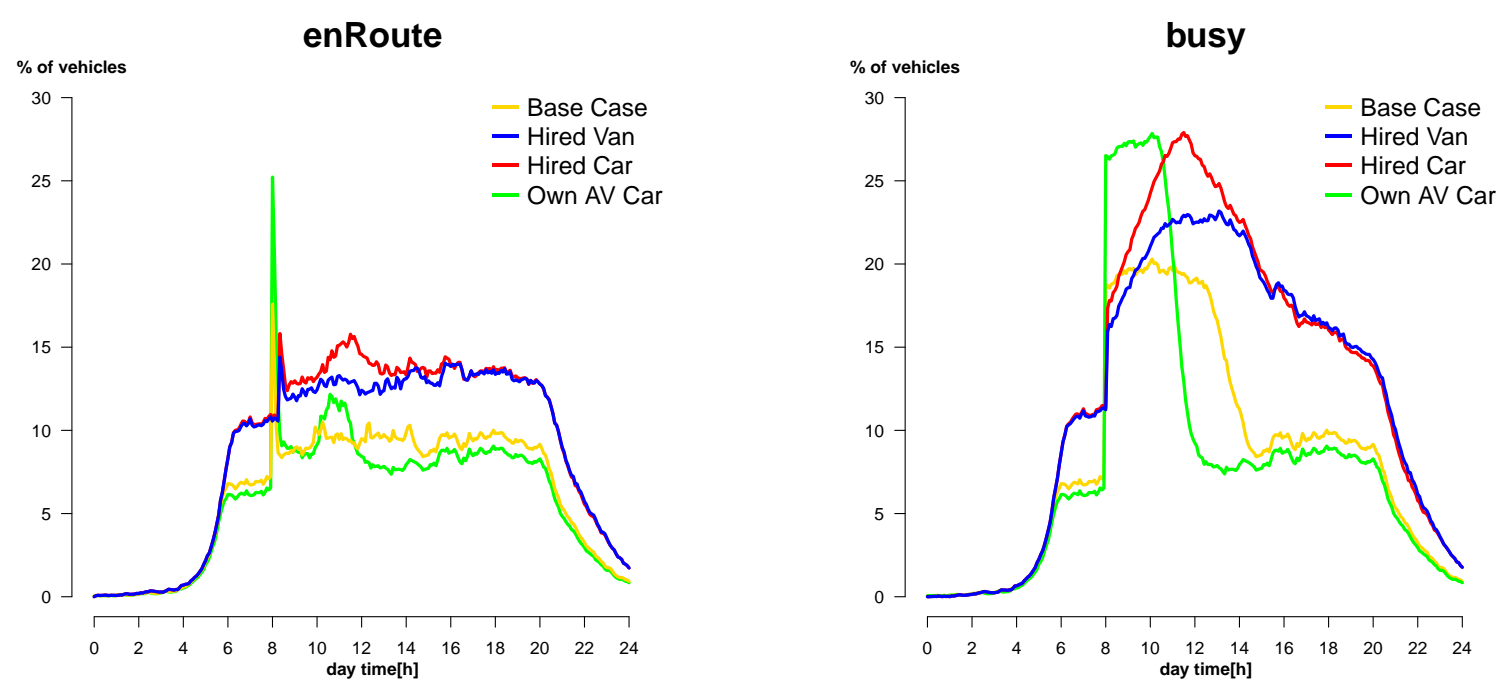

FIGURE 3 Time-variation of vehicles en route and busy vehicles

e.g. equip them with an already-loaded compartment. This means, for all simulations, the time needed for loading the compartment is not considered. As it is assumed that vehicles can be dispatched to a freight tour before the global delivery time window starts at 8 a.m., they might need to wait at the depot before it opens. This leads to additional wait time spent within the tour operation. For both vehicle types, the resignation of fleet ownership leads to an increase in the tour duration of roughly $30 \%$. Overall, the share of access and egress distance, as well as the share of time spent for retooling, increase with a growing number of tours.
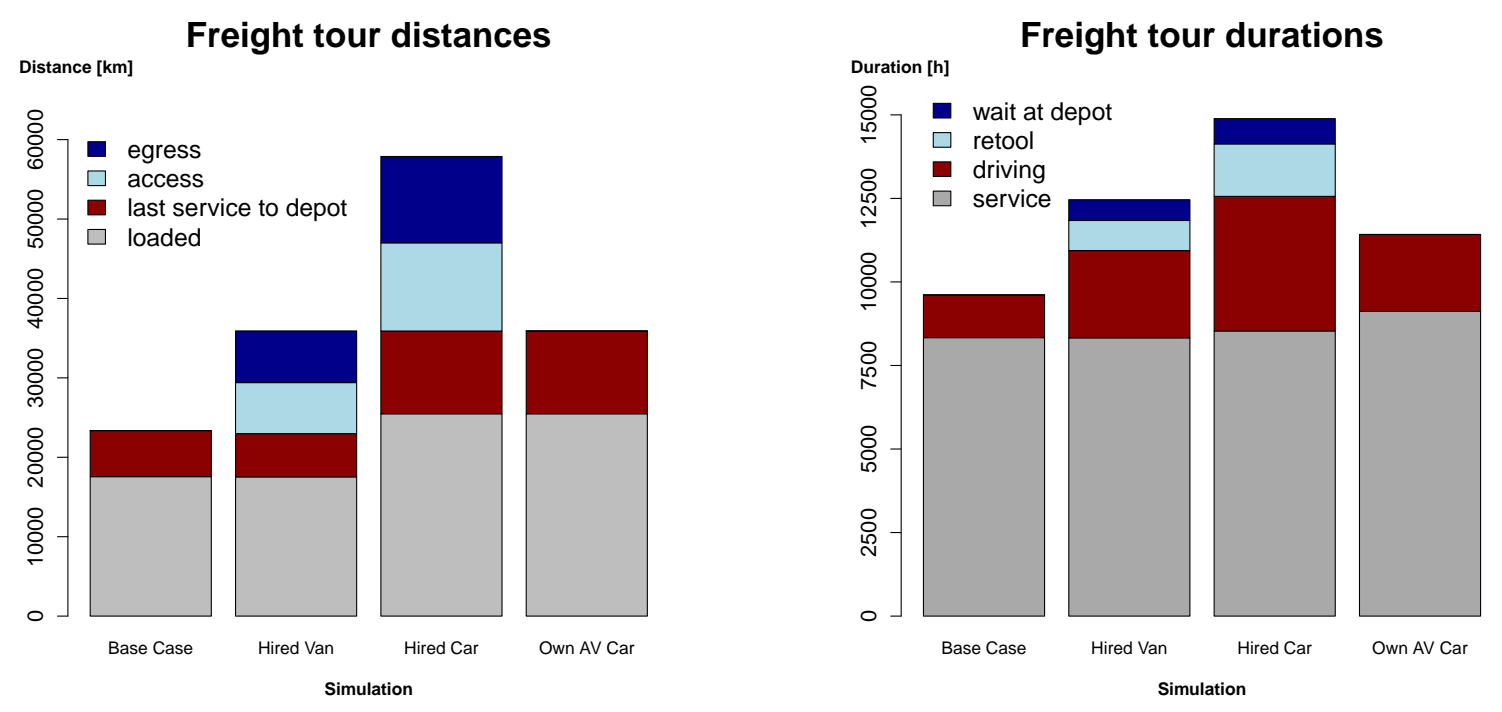

FIGURE 4 Impacts on tour distance and tour duration 


\section{Impacts on Operator and Economic Costs}

The operation pattern change not only has effects on the TSC itself but on the whole transport system. To investigate these impacts, the operation costs of the TSC $C_{T S C}$ as well as the overall economic costs $V$ are estimated. Let $P$ be the set of private vehicle owners in the system and let $i \in P$ be a single vehicle owner. As mentioned above, the journeys of the vehicle owners are assumed not to change neither in distance nor in time over the simulations. Therefore, the time costs $c_{\text {time }_{i}}$ and distance costs $c_{d i s t_{i}}$ of these rides are not part of the cost comparison and are set to zero here.

In each simulation, every vehicle owner $i$ that does not lend a vehicle to the TSC is assumed to possess a car. In the simulation "Hired Van" however, 1,751 owners lend their vehicle to the TSC which are assumed to be of van size and have the according cost structure. This means that the fleet of private vehicles is heterogeneous in this case. In the simulation "Hired Car", every private person possesses a car. Furthermore, for the following calculations, it is assumed that the TSC and the private person $i$ share fixed costs by 50\%. In a real world scenario, this incentive might not be sufficient for vehicle owners to provide their vehicle. However, price allocation may be the topic of a following study. With $x_{T S C}=0.5$ being the share of fixed costs borne by the TSC, the total fix costs $C_{f i x_{i}}$ of the private person $i$ can be computed by the following equation (see also Table 1):

$$
C_{f i x_{i}}= \begin{cases}5.1 € / \mathrm{d} & , \text { i has a car that is not hired by the TSC } \\ \left(1-x_{T S C}\right) * 5.1 € / \mathrm{d} & , \text { TSC hires a car from i } \\ \left(1-x_{T S C}\right) * 9.56 € / \mathrm{d} & , \text { TSC hires a van from i. }\end{cases}
$$

The total costs of the set of private owners result to

$$
C_{P}=\sum_{i} C_{f i x_{i}}
$$

Respecting the overhead $O_{T S C}$ per vehicle, the total operation cost of the TSC can be computed by

$$
C_{T S C}=\left(\beta_{f i x_{T S C}}+O_{T S C}\right) * x_{T S C} * n_{T S C}+\beta_{t i m e} * d u r_{T S C}+\beta_{d i s t} * d i s t_{T S C}
$$

with $n_{T S C}$ being the number of vehicles used by the TSC, $d u r_{T S C}$ the total tour duration and dist $_{T S C}$ the total tour distance. The total economic costs sum up to

$$
V=C_{P}+C_{T S C}
$$

Figure 5 shows the resulting costs for the TSC $C_{T S C}$ on the left hand side as well as the overall economic costs $V$ on the right hand side. Time costs (blue) only consist of driver wages. In the "Base Case", these make up approximately $77 \%$ of the operator costs. Thus, by switching to operation of AVs of the same type (van), the TSC could save a large amount of money. For easier comparison, an additional bar "Base Case automated" is displayed. For the TSC, operating its own fleet of car-like AVs seems not to be beneficial in comparison. 

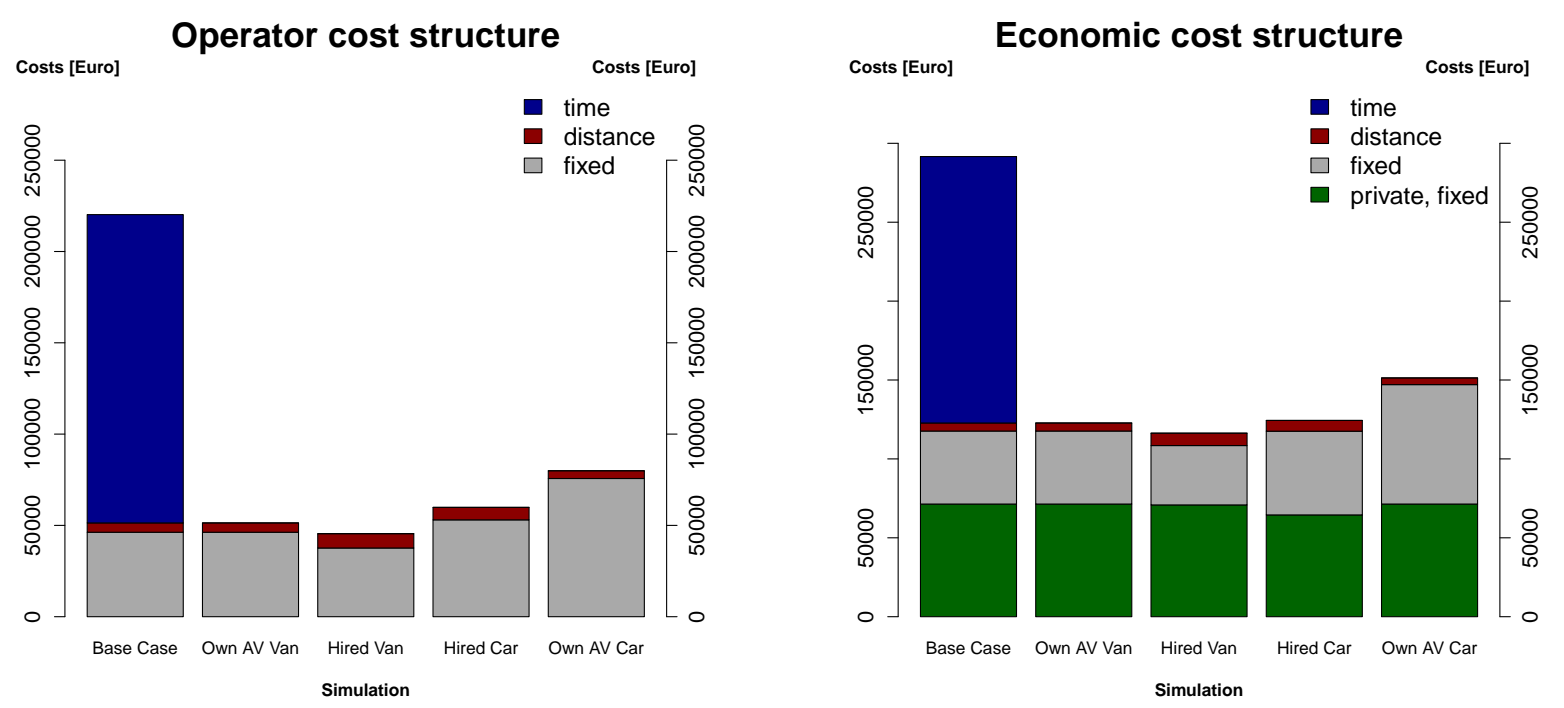

FIGURE 5 Impacts on operation and economic costs

By comparing the costs between "Base Case automated" and "Hired Van" or "Own AV Car" and "Hired Car" respectively, one can get an idea of the impact that the resignation of fleet ownership has on the TSC. Whereas the total costs for "Hired Car" only makeup $75 \%$ of "Own AV" they represent an increase of roughly $16 \%$ compared to "Base Case automated". The policy case "Hired Van" has the lowest cost of all, representing a reduction of roughly $12 \%$ compared to "Base Case automated". However, costs of the system transfer and risks such as the non-availability of vehicles are not taken into account. Moreover, depending on the upcoming technology, it might seem unlikely that private persons can provide vehicles with the parcel capacity of a current van. Thus, the question if resignation from fleet ownership is beneficial for parcel delivery needs further and more detailed investigation. By comparing the "Own AV" cases with the "Hired" cases, one recognizes the transformation of fixed costs into distance costs.

Looking on the economic costs $V$ on the right hand side of figure 5, one recognizes that the fixed costs for private person remain more or less stable for "Hired Van". This comes from the relation of the $\beta_{f_{i x}}$ values for the van and the car being very close to the share rate of fixed costs $x_{T S C}=0.5$. For "Hired Car" the sum of private fixed costs reduces by roughly $10 \%$. But, as more vehicles are needed, the TSC fixed costs overcompensate this reduction. In summary, the reduction of the overall fleet size by 1,814 vehicles through fleet ownership resignation by the service provider might lower the system's total costs by roughly 5\% ("Hired Van" versus "Own AV Van"). Automation on the other hand is associated with a much larger impact, reducing the economic costs by approximately $58 \%$.

\section{DISCUSSION AND OUTLOOK}

The results of this study strongly depend on the assumptions being made concerning the operation pattern of vehicles and the TSC, the amount and location of the depots and the vehicle cost parameters. Especially the economic cost comparison highly depends on the ratio of automated vehicles fixed costs for private persons versus a TSC. Moreover, this study disregards the internalization of external effects. As the change of the operation pattern comes with higher variable costs and 
particularly a higher amount of vehicle miles traveled, the external costs might affect the statement on overall economic costs. Nonetheless, this work provides a methodology to investigate such changes in operation that might be fed more detailed and accurate data in the future.

In MATSim, the technological step of automation of the vehicle's driving mechanism is simply modeled by declaring the driving agent as a machine. As MATSim represents a mesoscopic model, the actual driving behavior does not change. In the context of this study, the automation of parcel delivery execution also needs to be addressed. As the drop-off process is only modeled by the time needed to perform it, no detailed statements on the technical procedure need to be made. However, it is not clear what a fully automated parcel drop-off would look like. Special containers on the receiving side as well as appropriate technology such as a robotic arm on the vehicle side might be necessary. So far, different ideas such as mobile parcel containers have been developed. In a pilot project in Germany, vehicles served as a mobile parcel container themselves (29). But with smaller robots and drones, the industry also addresses the topic of automation with an approach that might get rid of last mile delivery using large vehicles entirely.

Future studies could investigate the dynamics of the market price that a TSC would pay private persons as function of demand, vehicle availability and time of day. This would also involve having a more detailed dispatch strategy, where declining freight tour requests or reaction to a low supply of vehicles is possible. As the dispatch algorithm used in this study is rather simple and not optimized, the decrease in operation costs by outsourcing the fleet might be underestimated. In operations research, modern dispatch algorithms try to predict the demand. For this use case, the TSC could also anticipate the availability of vehicles.

Another upcoming study could involve the TSC hiring vehicles not from private people but from another transport service company, for example a designated mobility-as-a-service-provider such as Uber or Lyft that is specialized in fleet management. Fleet vehicles are not fully occupied by passenger demand throughout the day and could be used in off peak times. Since there is no private owner, the hard constraint of a return time to a single customer could be swapped for a soft constraint that is subject to optimization of the fleet management.

\section{CONCLUSION}

This work provides a methodology to investigate the impact of resignation from fleet ownership by a TSC. This methodology is applied to the use case of a parcel delivery company in Berlin. The results suggest that the overall vehicle miles traveled increase in consequence of additional empty trips to and from the depots. Outsourcing the fleet can reduce the fixed costs for the TSC by approximately $10 \%$. However, costs for the system transfer and risks like vehicle non-availability are not taken into account. From an economic perspective, the system would profit from a change in the operation pattern as the overall number of vehicles in the system can be reduced. The use case presented strongly relies on assumptions concerning the operation pattern of vehicles and the parcel delivery, as well as vehicle cost parameters and spatial distribution of depots.

\section{ACKNOWLEDGMENT}

This work was partly funded by the German Federal Ministry of Transport and Digital Infrastructure - project number: 16AVF2147. The authors would like to thank William Charlton for proofreading the paper and Theresa Thunig for the help on mathematical formulations. 


\section{AUTHOR CONTRIBUTION STATEMENT}

The authors confirm contribution to the paper as follows: study conception and design: J. Bischoff, K. Martins-Turner, T. Schlenther; data collection: K. Martins-Turner, T. Schlenther; analysis and interpretation of results: J. Bischoff, K. Martins-Turner, K. Nagel, T. Schlenther; draft manuscript preparation: T. Schlenther. All authors reviewed the results and approved the final version of the manuscript.

\section{References}

[1] Litman, T., Autonomous Vehicle Implementation Predictions. Victoria Transport Policy Institute, 2019.

[2] Henao, A. and W. E. Marshall, The impact of ride-hailing on vehicle miles traveled. Transportation, 2018.

[3] Dias, F. F., P. S. Lavieri, V. M. Garikapati, S. Astroza, R. M. Pendyala, and C. R. Bhat, A behavioral choice model of the use of car-sharing and ride-sourcing services. Transportation, Vol. 44, No. 6, 2017, pp. 1307-1323.

[4] Bischoff, J., I. Kaddoura, M. Maciejewski, and K. Nagel, Simulation-based optimization of service areas for pooled ride-hailing operators. Procedia Computer Science, Vol. 130, 2018, pp. 816-823.

[5] Bischoff, J., M. Maciejewski, T. Schlenther, and K. Nagel, Autonomous vehicles and their impact on parking search. IEEE Intelligent Transportation Systems, 2019.

[6] Zhang, W., S. Guhathakurta, and E. B. Khalil, The impact of private autonomous vehicles on vehicle ownership and unoccupied VMT generation. Transportation Research Part C: Emerging Technologies, Vol. 90, 2018, pp. 156-165.

[7] Bösch, P. M., F. Becker, H. Becker, and K. W. Axhausen, Cost-based analysis of autonomous mobility services. Transport Policy, Vol. 64, 2018, pp. 76-91.

[8] Hölck, K., S. Höflich, and J. Wehinger, OEM oder Serviceanbieter? In Mobilität in Zeiten der Veränderung, Springer, 2019, pp. 527-541.

[9] Toyota Motor Corporation, Toyota Launches New Mobility Ecosystem and Concept Vehicle at 2018 CES, 2018, https://global.toyota/en/newsroom/corporate/ 20546438. html.

[10] Wörner, R., G. Arifaj, R. Rahmani, and T. Heisig, Geschäftsmodelle und Akzeptanzschwellen von hochautomatisierten Fahrerassistenzsystemen im Gütertransport. In Mobilität in Zeiten der Veränderung, Springer, 2019, pp. 133-151.

[11] Gebhardt, A., Entscheidung zum Outsourcing von Logistikleistungen. Schriften des KühneZentrums für Logistikmanagement, DUV Deutscher Universitäts-Verlag, s.1., 1st ed., 2006.

[12] Mourad, A., J. Puchinger, and C. Chu, Owning or sharing autonomous vehicles: comparing different ownership and usage scenarios. European Transport Research Review, Vol. 11, No. 1, 2019. 
[13] Horni, A., K. Nagel, and K. W. Axhausen (eds.) The Multi-Agent Transport Simulation MATSim. Ubiquity Press, 2016.

[14] Bischoff, J. and M. Maciejewski, Current and Future Dynamic Passenger Transport Services-Modeling, Simulation, and Optimization in a Sustainable Transport System. In Sustainable transportation and smart logistics (A. A. Juan, J. Faulin, P. Hirsch, and S. E. Grasman, eds.), Elsevier, Amsterdam, Netherlands, 2019, pp. 337-360.

[15] Nagel, K. and G. Flötteröd, Agent-based traffic assignment: Going from trips to behavioural travelers. In Travel Behaviour Research in an Evolving World - Selected papers from the 12th international conference on travel behaviour research (R. Pendyala and C. Bhat, eds.), International Association for Travel Behaviour Research, 2012, pp. 261-294.

[16] Maciejewski, M., A. Horni, K. Nagel, and K. W. Axhausen, Dynamic transport services. In The Multi-Agent Transport Simulation MATSim (A. Horni, K. Nagel, and K. W. Axhausen, eds.), Ubiquity Press, 2016, pp. 145-152.

[17] Maciejewski, M., J. Bischoff, S. Hörl, and K. Nagel, Towards a Testbed for Dynamic Vehicle Routing Algorithms. In Highlights of Practical Applications of Cyber-Physical Multi-Agent Systems: International Workshops of PAAMS 2017, Porto, Portugal, June 21-23, 2017, Proceedings (J. Bajo, Z. Vale, K. Hallenborg, A. P. Rocha, P. Mathieu, P. Pawlewski, E. Del Val, P. Novais, F. Lopes, N. D. Duque Méndez, V. Julián, and J. Holmgren, eds.), Springer International Publishing, 2017, pp. 69-79.

[18] Bischoff, J., N. Soeffker, and M. Maciejewski, A framework for agent based simulation of demand responsive transport systems, 2016.

[19] Zilske, M. and J. W. Jouber, Freight Traffic. In The Multi-Agent Transport Simulation MATSim (A. Horni, K. Nagel, and K. W. Axhausen, eds.), Ubiquity Press, 2016, pp. 155156.

[20] Turner, K., Agenten-basierte Modellierung und Simulation von Tourenplanung im städtischen Güterverkehr. Masterarbeit, TU Berlin, Berlin, 2015.

[21] Ziemke, D., I. Kaddoura, and K. Nagel, The MATSim Open Berlin Scenario: A multimodal agent-based transport simulation scenario based on synthetic demand modeling and open data. Procedia Computer Science, Vol. 151, 2019, pp. 870-877.

[22] OpenStreetMap, last accessed on 09 July 2019, http://www. openstreetmap.org.

[23] Raifer, M., overpass turbo, last accessed on 13 July 2019, https: / / overpass-turbo. eu/.

[24] Senatsverwaltung für Stadtentwicklung und Wohnen Berlin, Lebensweltlich orientierte Räume (LOR) in Berlin: Planungsgrundlagen. Berlin, 2019.

[25] Thaller, C., Strategische Verkehrsprognose: Rückkopplung einer makroskopischen Extrapolation mit einer mikroskopischen Verkehrssimulation. Dissertation, Technische Universität Dortmund, Dortmund, 2018. 
[26] Planco Consulting GmbH, Intraplan Consult GmbH, and TUBS GmbH, Grundsätzliche Überprüfung und Weiterentwicklung der Nutzen-Kosten-Analyse im Bewertungsverfahren der Bundesverkehrswegeplanung: Endbericht für das Bundesministerium für Verkehr und digitale Infrastruktur: FE-PROJEKTNR.: 960974/2011. Essen, Berlin, München, 2015, https://www.bmvi. de/SharedDocs/DE/Anlage/VerkehrUndMobilitaet/BVWP/ bvwp-2015-ueberpruefung-nka-endbericht.pdf?_blob= publicationfile.

[27] Zhang, L., T. Matteis, C. Thaller, and G. Liedtke, Simulation-based Assessment of Cargo Bicycle and Pick-up Point in Urban Parcel Delivery. Procedia Computer Science, Vol. 130, 2018, pp. 18-25.

[28] Vazifeh, M. M., P. Santi, G. Resta, S. H. Strogatz, and C. Ratti, Addressing the minimum fleet problem in on-demand urban mobility. Nature, Vol. 557, 2018, p. 534.

[29] Uhlemann, E., Connected-vehicles applications are emerging. IEEE Vehicular Technology Magazine, Vol. 11, No. 1, 2016, pp. 25-96. 